
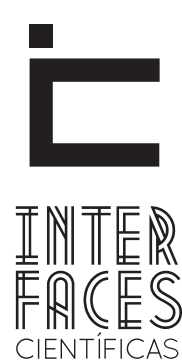

SAÚDE E AMBIENTE

ISSN IMPRESSO 2316-3313

ISSN ELETRÔNICO 2316-3798

\title{
ESCLEROSE MÚLTIPLA: IMUNOPATOLOGIA, DIAGNÓSTICO E TRATAMENTO - ARTIGO DE REVISÃO
}

\section{RESUMO}

A esclerose múltipla (EM) é conhecida pelos ingleses como esclerose disseminada e pelos franceses como esclerose em placas. Atinge principalmente adultos jovens, de gênero feminino, com etiologia multifatorial e ainda pouco conhecida. É uma doença inflamatória, crônica, desmielinizante do Sistema Nervoso Central, causando lesões disseminadas ou em placas na substancia branca e na medula espinhal. 0 diagnóstico é realizado pelos critérios de McDonald, juntamente com exames laboratoriais, do líquido cefalorraquidiano, imagens do cérebro e medula por ressonância magnética e anamnese do paciente. 0 tratamento hoje é realizado por imunossupressores e imunomoduladores, onde suas ações ainda são pouco conhecidas, porém estão apresentando bons resultados aos portadores de EM. Diante disso, essa pesquisa teve por objetivo descrever a definição, imunopatologia, diagnóstico e tratamento da EM. O método utilizado foi à pesquisa bibliográfica realizada nos sites Scielo, BIREME, NCBI e PubMed. Ainda são escassos trabalhos referentes a essa doença e os que existem estão meio vagos, com isso são necessárias pesquisas mais profundas em torno do percurso e etiologia da doença.

\section{PALAVRAS-CHAVE}

Esclerose Múltipla. Tratamento. Diagnóstico. 


\section{ABSTRACT}

Multiple sclerosis (MS) is known as disseminated sclerosis by the British and the French as sclerosis in slabs. Affects mainly young female adults with multifactorial etiology and still little known. It is an inflammatory, chronic, demyelinating disease of the central nervous system, causing disseminated lesions or plaques in the white matter and spinal cord. The diagnosis is made by the McDonald criteria along with laboratory tests of cerebrospinal fluid, brain imaging and spinal magnetic resonance imaging and patient's medical history. The treatment is now performed by immunosuppressants and immunomodulators, where its sha- res are still little known, but are showing good results to MS patients. Therefore, this study aimed to describe the setting, immunopathology, diagnosis and treatment of MS. The method used was the literature research conducted in SciELO, BIREME, $\mathrm{NCBI}$ and PubMed sites. There are still few studies concerning this disease and that there are a little sketchy, it is necessary further research around the course and etiology of the disease.

\section{KEYWORDS}

Multiple Sclerosis. Treatment. Diagnosis.

\section{RESUMEN}

La esclerosis múltiple (EM) es conocida por los ingleses como esclerosis diseminada, y por los franceses como esclerosis múltiple. Afecta principalmente a adultos jóvenes, el sexo femenino, con etiología multifactorial y todavía poco conocida. Es una enfermedad inflamatoria crónica, y es una enfermedad que afecta la mielina del sistema nervioso central,, causando lesiones o placas diseminadas en la sustancia blanca y la médula espinal. El diagnóstico se realizó según los criterios de McDonald, junto con las pruebas de laboratorio, el líquido cefalorraquídeo, imágenes del cerebro y la resonancia magnética espinal y la historia clínica del paciente. El tratamiento se realiza ahora por inmunosupresores, y sus acciones son aún poco conocidos, pero están demuestran buenos resultados para los pacientes con EM. Por lo tanto, este estudio tuvo como objetivo describir el escenario, la inmunopatología, el diagnóstico y el tratamiento de la EM. El método utilizado fue la investigación bibliográfica realizada en los sites Scielo, BIREME, NCBI y PubMed. Los trabajos aun son escasos en relación sobre esta enfermedad y los que existen son un poco vagos, Con eso es necesario seguir investigando en todo el curso la etiología de esa enfermedad.

\section{PALABRAS CLAVE}

La esclerosis múltiple. El tratamiento. Diagnóstico. 


\section{INTRODUÇ̃̃̃O}

A esclerose múltipla (EM) é conhecida pelos ingleses como esclerose disseminada e pelos franceses como esclerose em placas, está entre as mais vulneráveis das doenças neurológicas e como uma das mais importantes, devido à sua cronicidade e por acometer adultos jovens, entre 20-40 anos de idade. Afeta a substância branca do sistema nervoso central, podendo ocorrer múltiplas lesões espalhadas ou acometer grande região do encéfalo e medula espinhal. As lesões ocorrem por conta da destruição da bainha de mielina dos neurônios, levando, assim, a uma deficiência na condução motora (CARDODO, 2010).

Ela é a patologia desmielinizante mais comum do sistema nervoso central. É uma doença autoimune em que as células $T$ ativadas atravessam a barreira hemato-encefálica para iniciar uma resposta inflamatória, que conduz à desmielinização e lesão axonal. Os principais mecanismos responsáveis pela iniciação da doença ainda são desconhecidos (MARIN et al, 2014)

Ainda referente à doença, a sua fase inicial é sútil, sendo caracterizada por sintomas transitórios que duram entre cinco dias a uma semana. Essas características fazem com que o individuo não dê importância às primeiras manifestações clínicas da doença, já que os sintomas são transitórios (SANTOS, 2010). Com a progressão da EM o curso clínico toma a forma de episódios de surto e remissão de duração variável (de semanas até meses ou anos), caracterizados por déficits neurológicos, seguidos de recuperação parcial gradual das funções neurológicas. Essas recaídas tendem a diminuir à medida que a doença progride (KUMAR, 2010).

No que diz respeito ao processo da destruição da bainha de mielina, também chamado de desmielinização, não ocorre de forma simultânea em todo o encéfalo do SNC, mas sucessivamente em áreas ou placas do mesmo. Assim o portador apresenta sintomas va- riados, a depender da região afetada. Os mais comuns são fraqueza generalizada, fala com pronúncia alterada e tontura (SANTOS 2010).

Os portadores de EM são acometidos por um alto índice de fadiga, sendo este um sintoma que os tornam incapazes de realizarem as suas atividades diárias. Nesse caso, a fadiga é definida como "uma sensação subjetiva de perda de energia física e/ou mental, que é percebido pelo paciente ou por seus familiares, e interfere com a vontade e as atividades diárias", sendo denominada Fadiga Primária da EM (MENDES, 2007). Além da fadiga o portador é acometido por alto índice de depressão. 0 prejuízo visual unilateral é em consequência do envolvimento do nervo óptico (neurite óptica) que é uma manifestação frequente na EM (KUMAR, 2010).

Tratando-se das localidades de aparecimento da doença, a incidência maior ocorre nas regiões situadas entre os paralelos 44 e $64 \mathrm{~N}$, sendo consideradas áreas de alta incidência, aquelas com número de casos acima de 30/100000 habitantes; média incidência, áreas com números de casos entre 5 a 30/100000 habitantes e baixa incidência, com número de casos inferior a 5/100000 habitantes (GRZESIUK, 2006). A maior incidência da doença nas regiões distantes da linha do Equador, identificada pelos estudos epidemiológicos, não se explica pela localização geográfica, mas pelos atributos genéticos da população residente nessas áreas. São as características genéticas que definem a maior ou menor frequência de EM entre os indivíduos e não o local onde residem (TILBERY, 2005).

Em relação ao diagnostico, ele é clínico, com base no histórico relatado, na avaliação dos sintomas percebidos e relatados pelo paciente, juntamente com exames de Ressonância Magnética, Tomografia Computadorizada, análise do Líquido Cefalorraquidiano (que irá dosar as imunoglobulinas e pesquisar bandas 
oligoclonais para comparação com valores sanguíneos) e testes complementares (ZIEGELBOIM, 2010). Existe, também, um método de diagnóstico da EM realizado pelo Potencial Evocado Miogênico Vestibular (VEMP), que avalia a via vestíbulo-espinal a partir de mácula de sáculo (AIDAR, 2005).

No que diz respeito ao tratamento, os imunomoduladores têm demonstrado efeitos promissores, reduzindo o aparecimento de novas lesões, diminuindo a frequência de surtos e a progressão na forma remitente recorrente, diminuindo assim, também o acúmulo de incapacidade na evolução da doença (TILBERY, 2009). Porém ainda é pouco conhecida a ação destes, como também os seus efeitos colaterais.

Além disso, o tratamento segue diretrizes que ditam as regras necessárias para utilização desses medicamentos, como também determinam quais os pacientes que devem fazer uso dos mesmos. Hoje já existe o tratamento fisioterapêutico, sendo um tipo não invasivo de tratar os portadores de EM (TILBERY, 2009).

Sendo assim, o objetivo deste artigo foi relatar os aspectos atuais da esclerose múltipla, demonstrando como ela ocorre e também os métodos diagnósticos e de tratamento. Este trabalho foi realizado por meio de pesquisas das literaturas do período de 2005 a 2014, através do site BIREME, SCIELO, NCBI e PubMed como também em livros e teses, onde este tem por objetivo.

\subsection{DEFINIĈ̃O}

A Esclerose Múltipla (EM) é considerada uma doença autoimune, inflamatória e desmielinizante do Sistema Nervoso Central (SNC), com etiologia desconhecida, ainda que existam evidências de causas multifatoriais. Atinge principalmente adultos jovens, predominante do sexo feminino, de etnia branca e faixa etária entre 20 a 40 anos (SANTOS, 2010; MARIN et al, 2014). Essa doença é lenta e progressiva, com remissão de surtos, apresentando-se de formas diferentes de acordo com o tipo: a) Remitente recorrente
(RR); b) Secundariamente progressiva (SP); c) Primariamente progressiva (PP); e d) Progressiva recorrente (PR) (OLIVEIRA, 2007).

\subsection{ETIOLOGIA}

Ainda é pouco conhecida, mas supõe-se que as causas são multifatoriais, tais como: suscetibilidade genética, mecanismos autoimunes, exposição a fatores estressores, exposição à luz solar, tabagismo e infecções virais. Todos os estudos, englobando distribuição geográfica, dados migratórios e estudos epidêmicos, sugerem uma origem infecciosa. 0 aumento das bandas oligoclonais de imunoglobulinas no liquido cefalorraquidiano de 65 a 95\% dos pacientes com esclerose múltipla, evidencia uma infecção viral persistente, ou de um autoantígeno do SNC (CARDOSO, 2010).

\subsection{IMUNOPATOLOGIA}

As lesões encontradas nos portadores de EM são causados por uma resposta imune dirigida aos componentes da bainha de mielina. Por isso quando encontradas células inflamatórias crônicas dentro ou ao redor das placas da EM, juntamente com validação genética, a destruição da mielina é o foco de múltiplas investigações. Os estudos atuais indicam que a doença se inicia com células $\mathrm{T}$ CD4+, $\mathrm{T}_{\mathrm{H}} 1$ e $\mathrm{T}_{\mathrm{H}} 17$ que reagem contra antígenos da própria mielina e secretam citocinas. Células TH1 secretam IFN, que ativam macrófagos, e as células TH17 recrutam leucócitos. A desmielinização é provocada por esses leucócitos ativados e suas substancias lesivas. Nos infiltrados das placas e das regiões circunjacentes do cérebro consiste em células T CD4+ e, alguns CD8+ e macrófagos. Porém não se sabe como a reação imune é ativada, contudo foi proposto o papel de uma infecção viral para ativação das células T autorreativas, mas essa proposta é controversa (KUMAR, 2010).

A evolução da EM ocorre de diferentes maneiras. $\mathrm{Na}$ forma recorrente-remitente (RR) o paciente apresenta surtos bem individualizados que deixam ou não seque- 
las, não existindo progressão das deficiências entre os surtos. A forma secundariamente progressiva (SP) apresenta, anteriormente, um período de recorrências e remissões seguidas de progressão das deficiências, com ou sem surtos subjacentes. A primariamente progressiva (PP), caracteriza-se desde o inicio por doença progressiva, onde, na evolução, o paciente apresenta períodos de discreta melhora. Por último, a progressiva recorrente (PR), que, também, se caracteriza desde o inicio por doença progressiva, porém intercalada por surtos, com ou sem recuperação total, mas com progressão continua entre os surtos (OLIVEIRA, 2007).

Alguns clínicos sugerem ainda, a existência da EM benigna, quando os pacientes apresentam surtos e remissões iniciais com pouco ou nenhum déficit neurológico, após 10 anos do inicio da doença, podendo o paciente desenvolver a forma progressiva, posteriormente a Maligna, onde ocorre um desenvolvimento grave da EM progressiva primária, ao qual leva à morte fulminante, ou sobrevida de 5 anos após seu inicio (SANTOS, 2010).

A doença se inicia com sintomas neurológicos isolados ou por associação. Alguns portadores apresentam a primeira manifestação com sintomas sensitivos, motores ou com uma neurite óptica isolada. Síndromes dolorosas no inicio são raras, bem como afasia, alterações na cognição ou corticais. A presença de ataxia sempre estará relacionada com vertigem, diplopia, distúrbios motores e outros. No começo do quadro alguns pacientes têm queixas vagas como fadiga e mal-estar (TILBERY, 2005).

Durante recaídas (surtos), os portadores de EM perdem, parcial ou totalmente, algumas funções fisiológicas, identificadas por uma variedade de sintomas, como paralisia, hipoestesia, deficiência visual, diplopia ou ataxia. Os sintomas não dependem apenas da localização da lesão, mas também sobre a variedade de propriedades de condução exibidos nos axônios afetados. A causa central da produção de recaídas é a incapacidade de condução axonal no local da lesão, relacionado tanto com a inflamação quanto a desmielinização que atuam em fases sequenciais (SÁ, 2012).

Por conta da grande variabilidade de localização anatômica e sequencia temporal das lesões em pacientes com EM, as manifestações são variadas entre um individuo e outro. Os sintomas podem se desenvolver dentro de horas ou até vários dias ou semanas. É comum que os sintomas apareçam em 6 a 15 horas a depender do local e do tamanho da lesão. Os sintomas iniciais mais frequentes em ordem decrescente de frequência são: fraqueza motora, neurite retrobulbar, parestesias, marcha instável, visão dupla, vertigem e distúrbio de micção A depressão também é comum na EM (CARDOSO, 2010).

\subsection{DIAGNÓSTICO}

O diagnóstico se baseia na anamnese do paciente e exames físicos. Os critérios de McDonald, como mostrado na Tabela 1, juntamente com exames de ressonância magnética, potencial evocado e do liquido cefalorraquidiano (LCR) confirmarão o diagnóstico (ANDRADE 2007; SANTOS 2010).

O exame do líquor, em portadores de EM, é capaz de identificar a natureza inflamatória e imunológica das lesões do SNC, por meio de estudo qualitativo e quantitativo da resposta imunológica intratecal. Ele, também, contribui para diferenciação da EM de outras doenças, como neurossífilis, infecção por HTLV I/II, Lyme, dentre outras. Os testes liquóricos são divididos em essenciais (Bandas oligoclonais no LCR por focalização isoelétrica), complementares (Índice de IgG elevado, Celularidade $>4 / \mathrm{mm} 3$, Quociente de albumina (Qalb) $>7.10^{-3}$, indicando função anormal da barreira hemato-liquórica) e opcionais (Anticorpos poliespecíficos anti-rubéola e sarampo) (MACEL, 2002).

As proteínas totais estão elevadas no líquor em aproximadamente $40 \%$ dos portadores de EM, sendo esta elevação de tamanha importância para o diagnóstico, pois ela demonstra a disfunção da barreira hemato-en- 
cefálica. Essa disfunção é mais frequente na forma progressiva primária (MINISTÉRIO DA SAÚDE, 2010).

A quantificação da resposta imune humoral é realizada por meio da medida da concentração total de imunoglobulinas no LCR (fração gama da eletroforese), concentração absoluta do IgG, e de forma precisa pelo índice de IgG (IgG líquor/lgG soro $\div$ Albumina líquor/Albumina soro ). Outra análise quantitativa da resposta imune humoral intratecal é a síntese diária intratecal de IgG que tem correlação direta com o índice de IgG. (MACEL, 2002)

A avaliação qualitativa da resposta imune intratecal é realizada por meio de detecção de bandas oligoclonais. Essas bandas são imunoglobulinas (geralmente $\mathrm{IgG}$ ) definidas como duas ou mais bandas discretas na região gama que estão ausentes ou em menor intensidade na eletroforese concomitante de proteínas séricas e estão relacionada à síntese intratecal de anticorpos. Elas são sintetizadas por um ou poucos clones de plasmócitos, derivados de linfócitos $B$, em resposta à presença contínua de um antígeno único e altamente específico. Bandas oligoclonais de IgG são exclusivos do LCR e estão presentes em aproximadamente $95 \%$ dos pacientes com EM, sendo detectados por focalização isoelétrica.

A focalização isoelétrica é a técnica mais sensível para detecção dessas bandas, usando amostras paralelas do LCR e soro com a mesma concentração de IgG, coletadas simultaneamente. 0 método consiste em submeter essas matérias a uma eletroforese, onde o gel apresenta um gradiente de $\mathrm{pH}$, de modo a separar os diferentes tipos de IgGs com base em seus pontos isoelétricos. A visualização das bandas é feita por meio da coloração pela prata e detecção imunológica. As presenças dessas bandas indicam uma resposta imune direcionada contra um grupo restrito de antígenos mielínicos, indicando um mecanismo imunológico associado ao quadro clínico da EM. Embora não especifica da EM, essas bandas possuem elevada sensibilidade na doença (TILBERY, 2005).
A ressonância magnética se apresenta alterada em 87 a 95\% dos casos e mostra lesões hipointensas em T1 e hiperdensas em cortes com TR longo (T2, DP, FLAIR) e realce pelo contraste das lesões ativas. As áreas acometidas mais frequentemente são os centros semi-ovais, substância branca periventricular, corpo caloso, tronco cerebral, radiações ópticas, pedúnculos cerebelares, cerebelo, nervos ópticos e medula espinal (MACEL, 2002).

A necessidade de o paciente apresentar 2 surtos para o diagnostico, atualmente pode ser substituída por 1 surto associado à progressão de lesões à RM (novas lesões ou surgimento de impregnação pelo gadolínio em lesões anteriormente não impregnada, ou aumento de tamanho de lesões prévias), após o primeiro surto (POLMAN, 2005).

Na EM a tomografia computadorizada de crânio é alterada em 36 a 44\% dos casos, apresenta-se com áreas hipotensas na substância branca, alargamento ventricular e atrofia cerebral. As lesões ativas apresentam realce na fase contrastada (MACIEL, 2002).

Após o estabelecimento do diagnostico, deve-se estadiar a doença, ou seja, estabelecer seu estágio ou nível de acometimento por meio da Escala Expandida do Estado de Incapacidade (Expanded Disability Status Scale - EDSS). Essa escala possui vinte itens com escores que variam de 0 a 10, com pontuação que aumenta meio ponto conforme o grau de incapacidade do paciente. $\dot{E}$ utilizada para o estadiamento da doença e para monitorar o seguimento do paciente (TILBERY, 2009).

Existe ainda o potencial evocado miogênico vestibular (VEMP), que é um teste que avalia as lesões no tronco encefálico ou as que venham a comprometer a via vestíbulo-espinal, ele é realizado a partir de estímulos acústicos em forma de cliques a partir de fones de ouvido (AIDAR, 2005).

Os exames complementarem são dosagens de proteínas básicas da mielina, onde estas indicam 
destruição mielínica recente. Está aumentada em 70 a $90 \%$ dos portadores. Aparecem antes das bandas oligoclonais, sendo útil no momento inicial da doença (WALLACH, 2011). Devem ser realizados exames laboratoriais, como exames anti-HIV e VDRL e dosagem sérica de vitamina B12, no sentido de excluir outras doenças com características parecidas da EM. Deficiência da vitamina B12 e infecções por HIV apresentam quadros radiológicos parecidos com portadores de EM. O potencial evocado será exigido quando houver duvidas em relação ao acometimento do nervo óptico (MINISTÉRIO DA SAÚDE, 2010).

\subsection{TRATAMENTO}

O tratamento dos portadores de esclerose múltipla com imunomoduladores, e com imunossupressores, mudou o curso da doença nos últimos anos. 0 Ministério da saúde é o responsável pela liberação do uso desses medicamentos, que são: Interferon beta (INF) e o Acetato de glatirâmer (AG). Além disso, esse órgão, também, deliberou a distribuição gratuita para o tratamento por meio do Sistema Único de Saúde (SUS). Com a crescente demanda na prescrição desses medicamentos e por possuírem alto custo, houve a elaboração de protocolos e recomendações para o seu uso, sendo estes o processo de inclusão ou exclusão de portadores ao tratamento (DCNIABN, 2005). As recomendações são:

1- Quanto aos critérios de diagnóstico da doença: o diagnóstico deve ser realizado por meio dos critérios firmados pelo Painel Internacional para o diagnóstico da Esclerose Múltipla por Mc Donald e Cols, sendo bastante sensível e especifico (DCNIABN, 2005).

2- Para classificação das formas evolutivas da EM: vários ensaios clínicos demonstraram a ação diferenciada dos medicamentos em fases evolutivas distintas da EM, e com isso vários tipos de evolução foram aparecendo, porém, na prática, as quatro formas de evolução são: remitente-recorrente, secundariamente progressiva, primariamente progressiva e progressiva recorrente.
3- Para criação de centros de referências: a Secretaria de assistência à saúde do Ministério da Saúde criou o Grupo Técnico de Assessoramento em EM, com o intuito de assessorar os estados na tarefa de estimular a criação dos centros de referência.

4- Para uso de imunomoduladores: ditam regras necessárias para utilização dos medicamentos, como, a prescrição é exclusiva do neurologista, os imunomoduladores não podem ser utilizados em pacientes que não possuam sintomas e/ou sinais clínicos ou de RM da doença e etc.

Nos últimos anos diversos estudos estão demonstrando a ação das estatinas, que além de diminuir o nível de colesterol sanguíneo, apresentam, também, propriedades imunomoduladores e antiinflamatória, por causa da sua ação inibitória sobre o óxido nítrico sintase (NOS $\left.{ }^{a s e}\right)$ e citocinas pró-inflamatória, justificando assim a sua utilização como tratamento alternativo em portadores de EM. A utilização de Lovastatina e Sinvastatina em pacientes com EM, mostrou uma diminuição nas lesões visualizadas por ressonância magnética e ausência de efeitos colaterais graves (OLIVEIRA, 2007).

Apesar de efeitos não curativos, são conhecidos diversos benefícios dessas drogas, porém foram relatados em vários estudos efeitos colaterais, que se devidamente identificados e orientados, podem evitar a interrupção do tratamento. (TILBERY, 2009).

Segundo Tilbery (2009), na maioria das vezes os efeitos adversos são leves e transitórios e estão relacionados à má técnica de aplicação do medicamento e pode ser a principal causa da perda de adesão ao tratamento. A maioria dos pacientes recebem instruções na preparação e administração dos imunomoduladores, porém é importante avaliar a compreensão destas informações periodicamente.

O Interferon tem um papel importante no sistema imune por meio da produção de efeitos sobre as células 
T e B, influenciando na barreira hemato-encefálica. Vários mecanismos de ação têm sido propostos ao Ácido de Glutâmer, porém os seus efeitos biológicos ainda não estão completamente esclarecidos. Relata-se que o ácido de Glutâmer age inibindo as células T reativas, desviando-os da mielina, pressupõe-se, também, que ele suprime o sistema imune diminuindo assim a destruição da bainha de mielina (MENDES, 2011).

Segundo pesquisa de Mendes (2011), pacientes tratados com $20 \mathrm{mg}$ de AG diariamente, apresentaram redução de $29 \%$ da taxa de reincidência em um período de 2 anos. Ele reduziu, também, a progressão da incapacidade em $12 \%$. No entanto, existem os efeitos colaterais, sendo neste medicamento mais brandos, apresentando apenas uma reação no local da inoculação, como eritema e endurecimento.

Oliveira (2007) realizou acompanhamento de uma paciente com EM, diagnosticada de acordo com os critérios de McDonald, onde foi realizado primeiramente um tratamento com o Interferon, porém ela começou a apresentar efeitos colaterais levando-a a recusa do tratamento com drogas injetáveis. Foi então, oferecido outro meio de tratamento com a Rosuvastatina, não apresentando, após 6 meses de uso, nenhum efeito indesejável. Dois meses após inicio do tratamento a paciente apresentou uma boa evolução do quadro neurológico, passando a deambular distâncias maiores, a praticar exercícios físicos e não necessitar continuamente de sonda vesical. Após 6 meses de uso, apresentou queda do EDSS para 4,5 (antes 6,0) com melhora das funções piramidais e vesicais.

O equilíbrio corporal depende exclusivamente da integridade do sistema vestibular (labirinto, nervo, vestibulococlear, núcleos, vias e inter-relações no SNC), do sistema somatossensorial e da visão, sob coordenação do cerebelo. Um portador de EM apresenta uma lesão em algum desses sistemas, levando a conflitos de informações, surgindo assim, sintomas de desequilíbrio corporal e tontura. A principal forma de tratamento para essas disfunções vestibulares são medicamentosas, cirúrgicas e reabilitação vestibular (RV). Essa RV age fisiologicamente sobre o sistema vestibular por mecanismos centrais de neuroplasticidade conhecido como adaptação, habituação e substituição para obtenção da compensação vestibular (ZEIGELBOIM, 2010).

Nos últimos anos, além do tratamento invasivo existe também o tratamento fisioterapêutico que, segundo estudos, está apresentando resultados positivos quanto à movimentação física dos portadores como, também, melhora na sua qualidade de vida. O fisioterapeuta atua tanto na fase aguda (pós-surto) quanto na fase remissiva, tomando alguns cuidados. Na fase aguda, os exercícios devem ser mais passivos, as pausas de recuperação maiores, os exercícios objetivam basicamente, manter as amplitudes de movimento e evitar complicações secundárias. Pode-se também adicionar exercícios ativos sem muita perda energética. Já na fase remissiva os exercícios ativos serão mais intensos, mas intercalados por pausa de recuperação, de modo que não ocorram fadiga, nem aumento da temperatura corpórea, sendo estes, os fatores que causam surtos. Assim como orientar o paciente a se refrescar, tomando banho de água fria após os exercícios ou ingeri-la (CARDOSO, 2010).

\section{CONSIDERAÇÕES FINAIS}

Em todos os estudos pesquisados foi constatado predominância dessa patologia em adultos jovens, do sexo feminino. Acomete a substância branca do SNC, causando lesões múltiplas ou em placas. Não possui etiologia definida, porém pressupõe ser uma doença multifatorial.

Os sintomas apresentados pelos portadores dependem do tamanho, como também do local da lesão. No inicio da doença os sintomas são sutis, que gra- 
dativamente, com a evolução da doença, tornam-se incapacitantes.

0 diagnóstico é pungente, tanto para o médico quanto para o paciente, pois estes não sabem o prognostico da doença. Os critérios hoje utilizados para confirmação do diagnostico são os de McDonald, elaborado com base no Painel Internacional sobre Diagnóstico de EM, sendo este citado por todos os autores pesquisados. Os exames realizados englobam exames do LCR para pesquisa de bandas oligoclonais, Imagem por Ressonância Magnética e outros complementares, como dosagem vitamina B12, VDRL, anti-HIV. Existe, também, os exames de Potencial Evocado Miogênico vestibular, que avalia as lesões do tronco encefálico que comprometam a via vestíbulo-espinal.

O tratamento por imunossupressores, como também o tratamento fisioterapêutico estão melhorando a vida dos portadores, diminuindo os surtos e, aumentando a qualidade de vida por exercícios físicos. Atualmente, existe o uso das estatinas para tratamento na $E M$, onde além de diminuir o colesterol estão tendo efeito anti-inflamatório e imunossupressores, apresentando ainda menos efeitos colaterais comparados aos imunossupressores.

Existe, também, o transplante de células tronco, porém ainda é um protocolo de pesquisa e indicado na refratariedade terapêutica. Esse método mostra uma estabilização clínica, mas não uma melhora objetiva.

Ressalta-se a escassez de publicações sobre o assunto abordado, o que demonstra a necessidade do aprofundamento técnico cientifica referente ao assunto mencionado. Entretanto, com as inovações tecnológicas houve uma progressão em relação ao diagnóstico e ao tratamento. Porém novos estudos deve ser realizados, principalmente sobre os efeitos secundários da doença como também se deve buscar a etiopatogenia da mesma.

\section{REFERÊNCIAS}

AIDAR, R.C. e Cols. Potencial evocado miogênico vestibular: novas perspectivas diagnosticas em Esclerose múltipla. Revista Brasileira de Otorrinolaringologia, v.71, n.1, Jan/Fev 2005, p. 48-54.

ANDRADE, R. E. M. e Cols. Evaluation of white matter in patients with multiple sclerosis through diffusion tensor magnetic resonance imaging. Arquivo de Neuropsiquiatria, 2007, 65 (3-A): 561-564.

CARDOSO, F. A. G. Atuação fisioterapêutica na Esclerose Múltipla forma recorrente-remitente. Revista Movimenta, v.3, n.2, 2010, p. 69-75. Disponível em: <www.nee.ueg.br>. Acesso em: 25 fev. 2013.

Departamento Científico de Neuroimunologia da Academia Brasileira de Neurologia (Dcniabn). Diretrizes para o tratamento de esclerose múltipla com drogas imunomoduladoras. Arquivo de Neuropsiquiatria, 2005, 63 (3-B): 892-895.

GRZESIUK, A.K. Características clínicas e epidemiológicas de 20 pacientes portadores de Esclerose Múltipla acompanhados em Cuiabá - Mato Grosso. Arquivo de Neuropsiquiatria, 2006, 64(3-A): 635-638.

KUMAR, V.; ABBAS, A.K.; FAUSTO, N.; ASTER, J.C. Robbins e Cotran - Patologia: bases patológicas das doenças. 8.ed. Rio de Janeiro: Elsevier, 2010, p. 1320-1321.

MACIEL, E. P. Esclerose Múltipla: correlação clínica, Líquido cefalorraquiano e neuroimagem. Tese (doutorado) Universidade Estadual de Campinas. Campinas, São Paulo: [s/n], 2002.

MARIIN, N.; EIXARCH, H.; MANSILLA, M. J.; RODRÍGUEZ-MARTÍN, E.; MECHA, M.; GUAZA, C.; ALVAREZ-CERMEÑO, J.C.; MONTALBAN, X.; VILLAR, L.M.; ESPEJO, C. Anti-myelin antibodies play an important role in the susceptibility to develop proteolipid protein-in- 
duced experimental autoimmune encephalomyelitis. Clin. Exp. Immunol. 2014, 175 (2): 202-7

MENDES, M. F. Fadiga na Esclerose Múltipla. Revista de Neurociências, v.15, n.3, São Paulo, 2007, p. 181. Disponivel em: <www.revistaneurociencias.com.br>. Acesso em: 13 fev. 2013.

MENDES, A. e Cols. Classical immunomodulatory therapy in multiple sclerosis. Arquivo de Neuropsiquiatria, 2011, 69 (3): 536-543.

\section{MINISTÉRIO DA SAÚDE. Protocolo clínico e diretri-} zes terapêuticas Esclerose Múltipla. Portaria n 493 , de 23 de Setembro de 2010. Disponível em: <www. portal.saude.gov.br>. Acesso em: 18 mar. 2013.

OLIVEIRA, M. R. e Cols. Uso de Rosuvastatina em Esclerose Múltipla. Revista de Neurociências, v.15, n.3, São Paulo, 2007, p. 246-250. Disponível em: <.revistaneurociencias.com.br>. Acesso em: 13 fev. 2013.

PAVAN, K. e Cols. Avaliação da fatigabilidade em pacientes com esclerose múltipla através do dinamômetro manual. Arquivo de Neuropsiquiatria, 2006, 64(2-A): 283-286.
POLMAN C.H. e Cols. Diagnostic criteria for multiple sclerosis: 2005 revisions to the "McDonald criteria". Ann Neurologia, 2005, 58: 840-846.

SÁ, M. J. Physiopathology of symptoms and signs in multiple sclerosis. Arquivo de neuropsiquiatria, 2012, 70(9): 733-740.

SANTOS, G. B. Esclerose Múltipla: relação socioambiental. Revista Hórus, v.4, n.2, Ourinhos-SP, 2010, p. 208-219. Disponível em: <www.faeso.edu.br/horus>. Acesso em: 13 fev. 2013.

TILBERY, C. P. Esclerose Múltipla no Brasil: aspectos clínicos e terapêuticos. São Paulo: Atheneu, 2005.

TILBERY, C. P. e Cols. Efeitos adversos no tratamento da Esclerose Múltipla com drogas imunomoduladoras experiência em 118 casos. Revista de Neurociência, 2009, 17(3): 220-225. Disponível em: <www.revistaneurociencias.com.br>. Acesso em: 13 fev. 2013.

ZEIGELBOIM, B. S. e Cols. Reabilitação vestibular: utilidade clínica em pacientes com Esclerose Múltipla. Revista da Sociedade Brasileira de Fonoaudiologia, v.15, n.1, Curitiba-PR, 2010, p. 125-128. dade Tiradentes (1998) e mestrado em Pesquisas laboratoriais em Saúde Pública - Coordenadoria de Controle de Doenças do Estado de São Paulo (2005). E-mail: dfragata@yahoo.com.br 